\title{
Dokuma Kumaş Tasarımında Yaratıcılık İçin Bir Yöntem Önerisi
}

\author{
Havva HALAÇELII METLIOC̆LU*
}

Özet

Günümüz giysilik kumaş modasında son yıllarda tüvit, kazayağı, merdiven gibi klasik görünümlü kumaşların yeni malzeme ve teknolojik işlemlerle yorumlanarak güncellendiği görülmektedir. Buradan hareketle, bu çalışmada, lisans eğitimi gören ve dokuma tasarım dersi alan öğrencilerin renk örgü efektleri ile elde edilen klasik kumaş tasarımını yeni bir yorumla atkı lanseli yapı ile elde ederek yaratıcılıklarını geliştirmeleri ve dokuma kumaşlar için yeni yüzeyler elde etmeleri hedeflenmiştir. Öğrenciler, bir sinema filminden yola çıkarak seçtikleri tema doğrultusunda kumaşın fiziksel ve estetik tasarım unsurlarını oluşturan renk, malzeme seçimi, örgü ve yapıyı etüt ederek tasarım yapmışlardır.

Anahtar Sözcükler: Dokuma, Kumaş, Tasarım, Yaratıcılık, Renk-Örgü Efektleri.

\section{A Proposal of Methodology for Creativity in Woven Fabric Design}

\section{Abstract}

In recent years, classical woven fabrics such as tweed, pie de poule, shark skin are reproduced with new materials and technological processes, and updated within the concept of contemporary fabric trends. Therefore, in this paper, it is aimed to motivate bachelor degree students who are enrolled to weaving design courses to approach to the classical fabrics with new interpretation and to develop their creativity by using different techniques such as overshot weaves and create new surface effects. Inspired by a movie that they have chosen, students produced their designs by examining the physical and aesthetical design features of the fabric such as color, material, weave and structure.

Keywords: Weaving, Fabric, Design, Creativity, Color-Weave Effects. 


\section{Giriş}

Yaratıcılık, tüm üretim alanlarında olduğu gibi, tekstil ve dokuma kumaş tasarımında da ürünün diğerlerinden ayırt edilmesini, kullanıcı tarafından daha çok ilgi çekmesini ve talep edilmesini sağlayan bir unsurdur. Bu nedenle yaratıcılık, yeni bir fikrin kuluçkalanması ile eskiz ve karalama sürecinde ortaya çıkabileceği gibi, malzeme ve tekniğin bütünsel anlayışla ele alındığı prototip tasarım ve üretim aşamalarında da etkin olmaktadır. Bu nedenle, kumaşın dokunarak fiziksel bir varlığa dönüşebilmesi için kullanılacak malzemenin türü ve inceliği, renk ve dokusu, dokuma tekniği, kumaşı oluşturacak örgü, kumaş yapısı ve bitim işlemleri gibi teknik unsurların belirlenmesinde de yaratıcılık rol oynamaktadır (Halaçeli, 2011: 575-578). Tasarımcının üzerine düşen görevlerden birisi daima yeni ve farklı olanı aramak; malzeme, teknik ve yapı ile ilgili yeni yorumlar getirmek; estetik ve fiziksel anlamda da yaratıcılığı ortaya çıkarmaktır.

Diane Sheehan ve Ann Sutton (1989:32), Ideas in Weaving adlı kitaplarında bu konuya “...dünyanın iki düşünce okulundan oluştuğu düşünülebilir. Mantık ve düzen üzerine kurulu klasik düşünce; sezgi ve duygu üzerine kurulu romantik düşünce. Aslında birbirinden tamamen uzak bu iki düşünce arasında, fiziksel dünyaya ait akıl ile bilinçaltındaki duygu ve rüyalarla kararlar alırız." şeklinde değinmektedir. Bu çalışmaya konu olan dokuma kumaş tasarımında yaratıcılık için bir yöntem önerilirken, öğrencilerin bir sinema filminden yola çıkarak, sezgi ve duyguları ile hareket edip ilham alması, renk örgü efektlerini atkı lanseli yapılarla bir düzende yorumlaması amaçlanmıştır.

Sinemanın kumaş tasarımında yaratıcılığı nasıl etkilediği konusu kapsamında, Çukurova Üniversitesi, Güzel Sanatlar Fakültesi, Tekstil Tasarım Bölümü'nde 20122013 Bahar döneminde yürütülmüş olan Dokuma Tasarım 3 dersini alan 7 öğrencinin çalışmalarına yer verilmiştir.

\section{Amaç ve Yöntem}

Dokuma kumaş tasarımında yaratıcılık, yeni malzemelerin, tekniklerin ve teknolojik işlemlerin uygulanması şeklinde ortaya çıkarılabileceği gibi, var olan klasik bir kumaş deseninin yeni yapı, malzeme ve teknolojik işlemlerle yorumlanarak ele alınması şeklinde de gelişebilir. Dokuma tekniği ile üretilen tekstil ürünlerinde desen ve renk, ürünün fiziksel yapısı ile birlikte elde edildiğinden, ürün rengi ve tekrar sistemlerine dayalı desenle birlikte tasarlanmaktadır (Saçlıoğlu vd., 2007: 39). Bu nedenle, bu çalışma kapsamında bir sinema filminden ilham alınarak klasik görünümlü tüvit, kazayağı, balıksırtı ve merdiven efektlerinin atkı lanseli yapılarda atkı lanse ipliği olarak kullanılması ve renk-örgü efektlerinin tekrar sistemlerine bağlı kalınarak yeni kumaş desenleri ve dokularının elde edilmesi amaçlanmıştır.

Dokuma kumaş tasarımı, tema, çıkış noktası, renk ve doku ile birlikte yüzey tasarımına bağlı olarak malzeme, yapı ve dokuma yöntemi (armürlü veya jakarlı) seçimini de kapsamaktadır. Seçim yapma, tasarımcının yaratıcı sürecinde bilgi ve sezgilerini kullanması bakımından çok önemlidir. Tasarım sürecinde öğrencilerden izledikleri bir filmden yola çıkmaları istenmiş ve filmin konu, mekan, kostüm ve hikayesinden ilham alabilecekleri belirtilmiştir. Her öğrenci seçmiş olduğu filmden yola çıkarak renk ve malzeme araştırması ile doku araştırması yapmış ve kumaşın yüzey tasarımı için renk -örgü efektleri ile eskizler hazırlamıştır. Eskiz yüzeylerinde oluşturdukları kompozisyonları, atkı lanseli yapı kullanarak kumaş yüzeyine aktarmışlardır. Bu kapsamda, dimi, zigzag, balıksırtı, diyagonal, merdiven ve kazayağı desenleri incelenmiştir.

Öğrenciler, tasarım sürecinde renk seçimlerini tasarım temalarına bağlı olarak yapmışlardır. Malzeme seçiminde ise, atkı ipliği olarak kullanılacak iplikler fanteziden ziyade, daha düz seçilerek iplik karakterine bağlı dokusal özellikler yerine yapı ile elde edilen dokunun öne çıkması hedeflenmiştir.

\section{Renk Örgü Efektleri ve Lanseli Yapılar}

Renk-örgü efektlerinin desen oluşturma açısından önemine değinilecek olursa, kumaşlar, örgüleri ve kaliteleri açısından olduğu kadar desenleri ve renkleriyle de özen- 
dirici olmalıdır. Bunu elde etmek için çeşitli yöntemler uygulanarak kumaşların görüntülerinde değişiklik yapılabilir (İmer, 1997: 124). Atkı ve çözgü ipliklerinin belirli bir düzende ve renk dizilimi ile biraraya gelmesi ile çeşitli motifler elde edilip, yüzey dokuları oluşturulabilir. Dokuma kumaşlarda desen, birim doku ve motifin atkı ve çözgü ipliklerinin belirli bir örgü düzenlenmesinde biraraya getirilmesi ile elde edilir. Örgülerin bağlantılarından yararlanılarak çözgü ve atkı iplik gruplarından birine ya da her ikisine belirli düzenlerle değişik renkler uygulanarak elde edilen görünüşlere renk efektleri denir (Acuner, 2001: 101).

Lanseli (atkı takviyeli) dokuların özellikleri incelenecek olursa, lanseli yapılar, bezayağı, dimi, saten ve krep gibi temel bağlama türleri ile dokunan, değişik figürlerin özel ipliklerle doku içine işlendiği motifli dokulardır. Çözgü ve atkı yönünde eklenen bu iplikler parlaklıkları, renkli oluşları ve materyal çeşitleriyle dokusal yüzeyi süslerler. Diğer işlemeli kumaşlardan farkı, daha ziyade dokunun tersini kaplayan lanse ipliklerinin dokunun ön yüzünde sadece motif ve figür olarak görünmesidir (İmer, 1987: 87). Atkı lanseli yapılarda motifler, atkı lanse ipliğinin zemin dokuya ve desene göre olan bağlantısıyla elde edilir (İmer, 1987: 90) (Resim 1-2).

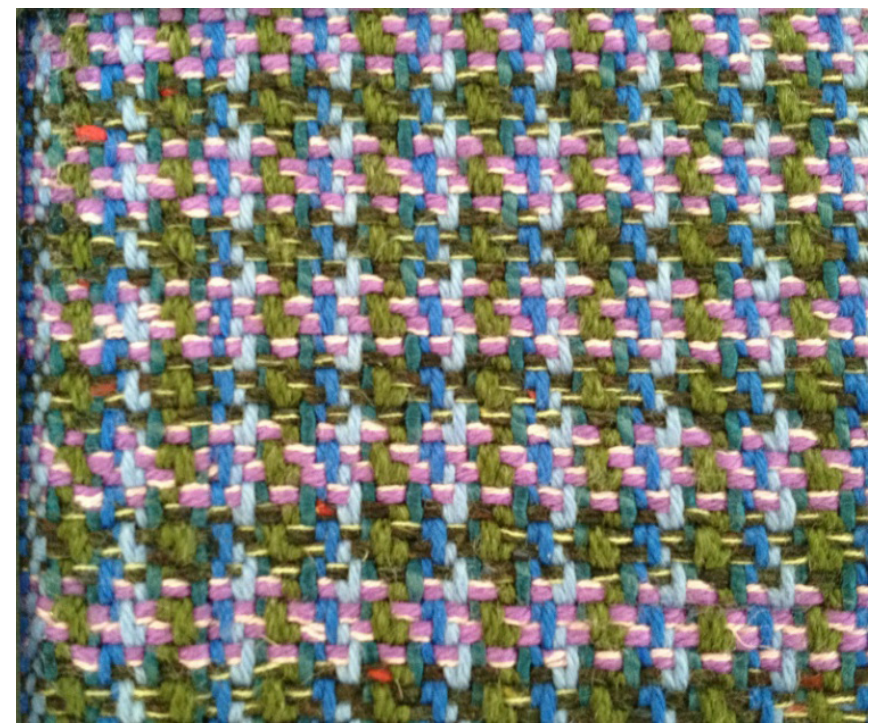

Resim 1. Gülşah Bakır, renk-örgü efektli kumaş tasarımı, 2012.

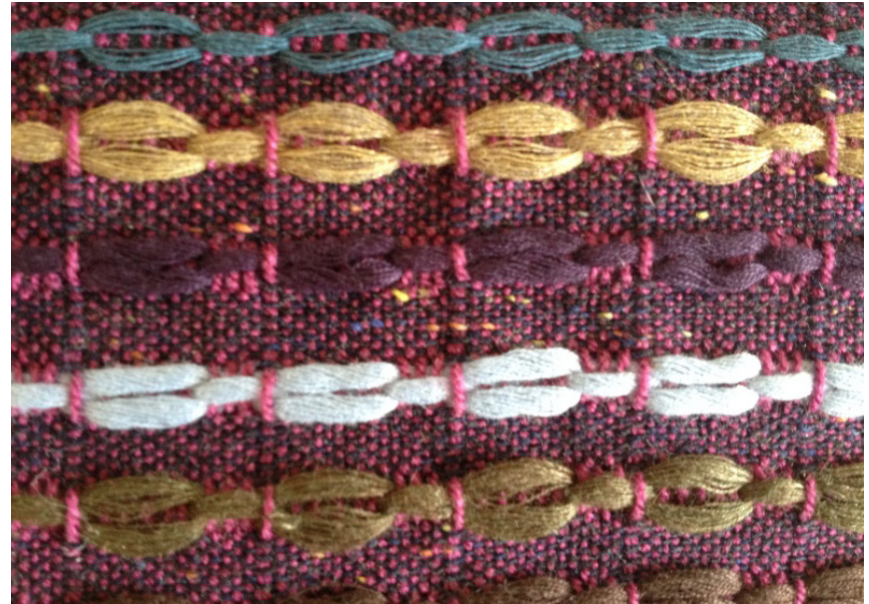

Resim 2. Özge Çetinkaya, atkı lanseli kumaş tasarımı, 2013.

\section{Tasarımlar}

\section{Tasarım 1}

Çıkış noktası: Şeytan Marka Giyer (2006). Öğrenci, filmin geçtiği New York atmosferindeki bir binadan yola çıkmış, filmin ana karakteri Andy Sachs'ın moda dünyasında çektiği zorluklarla ilişki kurmuştur. Dimi D 1/13 s yönlü örgüyü sol köşesinde dikey bir bağlantı çözgüsü ekleyerek atkı lanseli düzende yorumlamıştır. Zemin örgü olarak bezayağı örgü seçilmiş, atkı yoğunluklu bir örgü seçilmesi ile kumaş yüzeyinde atkı ipliklerinin görünürlüğü artmıştır. Zemini oluşturan bez ayağı örgüde, rayon ve pamuk ipliği kullanılıken lanse için kullanılan polyester iplikler yüzeyde parlak bir etki yaratmıştır.

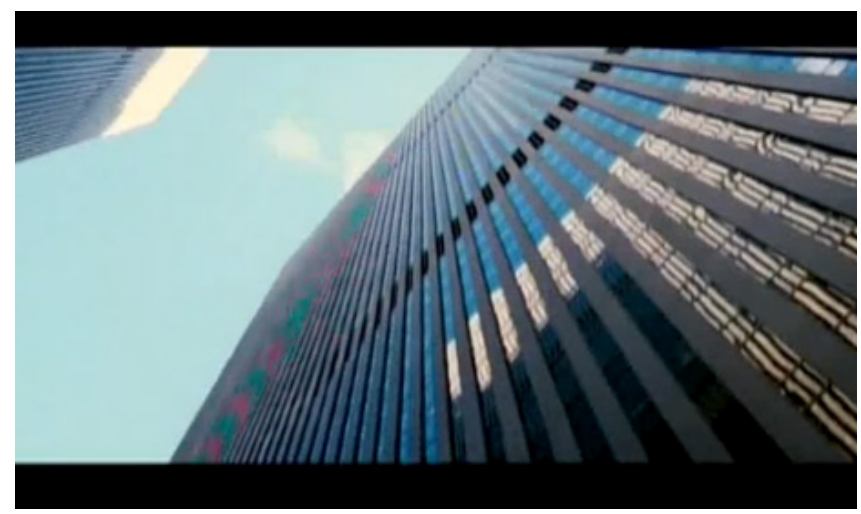

Resim 3. Şeytan Marka Giyer filminden bir sahne. 


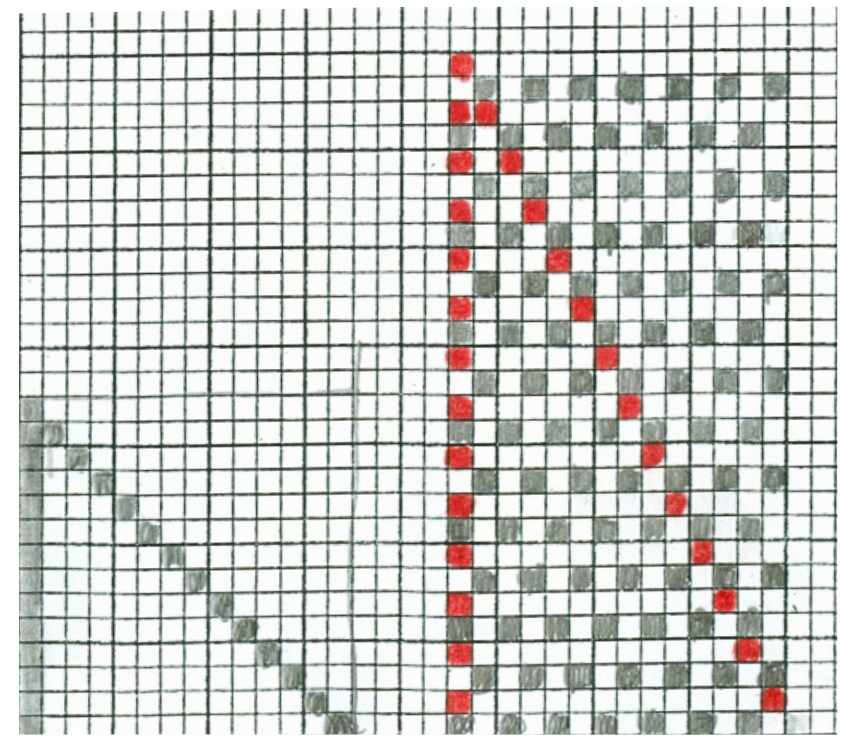

Resim 4. D 1/13 s örgüsü ve lanseli yapı ile açııımı, tam tekrarlı görünümü.

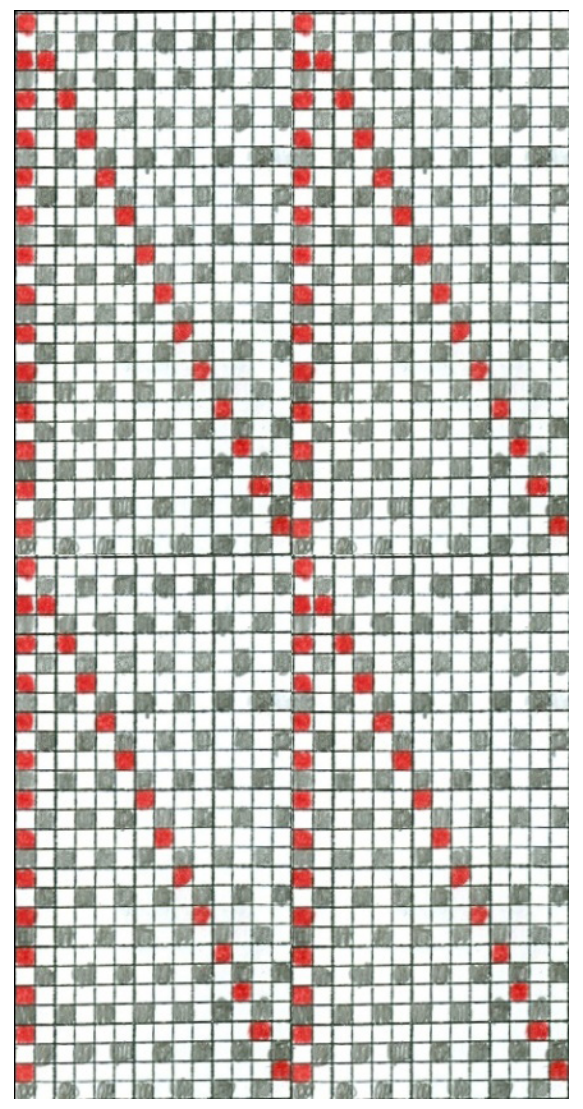

Resim 5. D 1/13 s örgüsü ve lanseli yapı ile açılımı, tam tekrarlı görünümü.

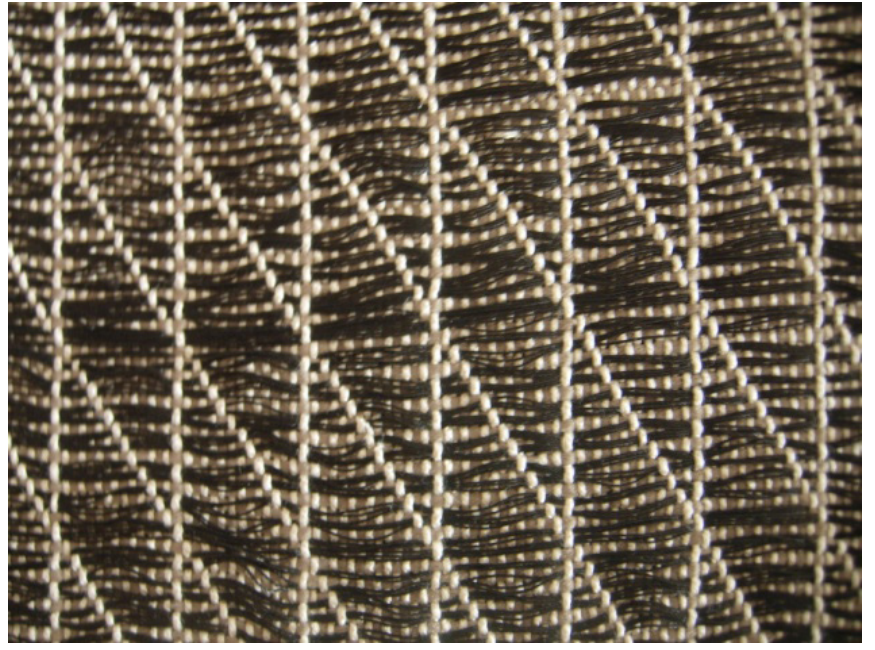

Resim 6. Giysilik kumaş tasarımı, Jiyan Erkil, 2013.

\section{Tasarım 2}

Çıkış noktası: Aşk Geliyorum Demez (2009). Öğrenci, Aşk Geliyorum Demez filminde, boşaltılması istenen han imgesinden yola çıkmıştır. Hanın dış cephesindeki simetrik düzen, balıksırtı örgü ile yorumlanmıştır. Balıksırtı örgü düzeninde kurgulanan tasarımda lanse atkı ipliklerinin atılması ile sağlam ve dayanıklı bir yüzey elde edilmiştir. Zemin örgü bez ayağı seçilmiştir. Benzer bir görünüm, tek katlı yapı ile elde edilebilecekken lanse ipliklerinin yüzmesi ile yüzeyde daha dolu ve yoğun bir doku oluşmuştur.

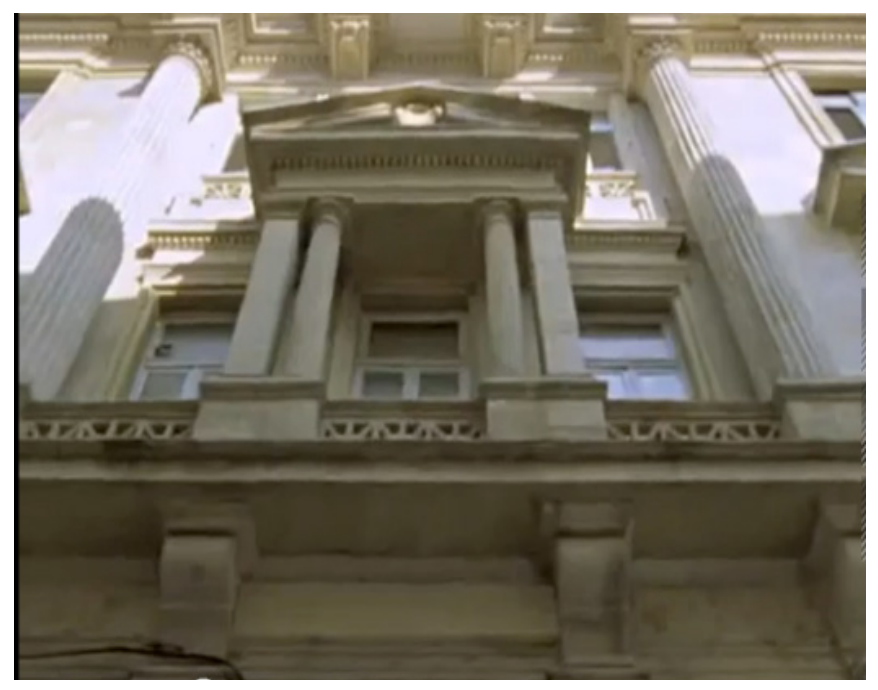

Resim 7. Aşk Geliyorum Demez filminden bir sahne. 


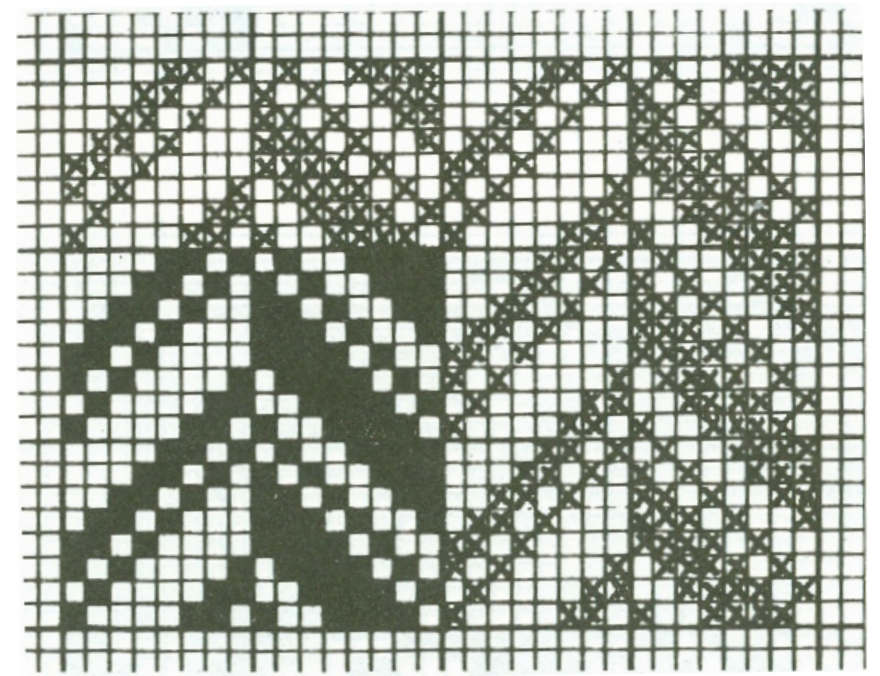

Resim 8. Balıksırtı örgü (Şeber ve Alpan, 1989: 37).

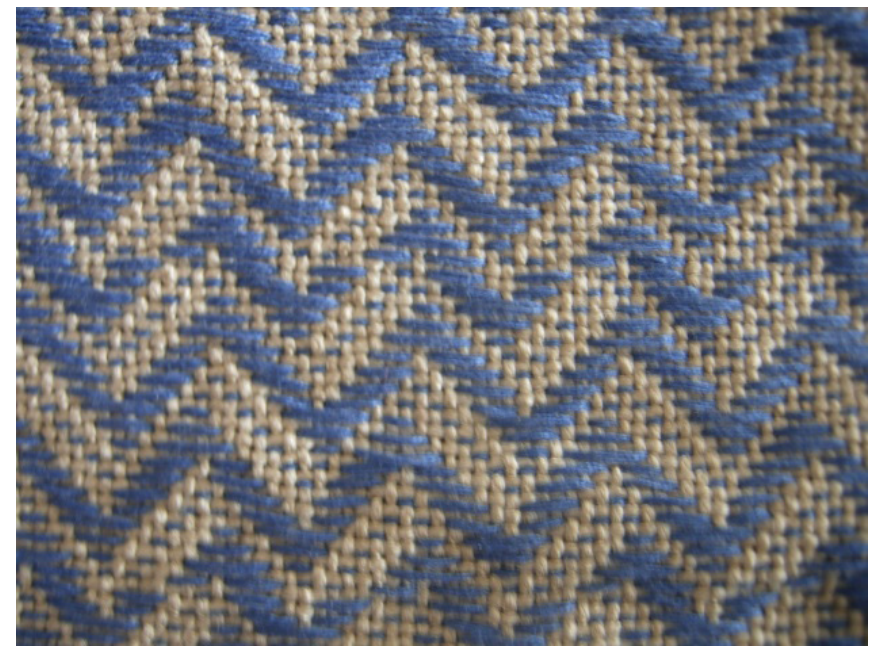

Resim 9. Giysilik Kumaş Tasarımı, Ecem Baki, 2013.

\section{Tasarım 3}

Çıkış noktası: Melekler ve Şeytanlar (2009). Bu tasarımda öğrenci, filmin afişindeki renklerden yola çıkmış, filmin temasındaki şeytan imgesini kırmızı ve siyah renklerle ilşkilendirilmiştir. Pamuklu iplikle birlikte yünlü iplik kullanılmıştır. Motifli diyagonal örgüde atkı olarak görülen alanlar atkı lansesi olarak değerlendirilmiştir. Zemin örgü için bez ayağı seçilmiştir. Renk seçiminde filmin genel atmosferinden yola çıkılıp kırmızı ve siyah seçilirken, belirgin motif düzenlemeleri yerine yüzeyde dokusal bir görünüm elde edilmiştir.

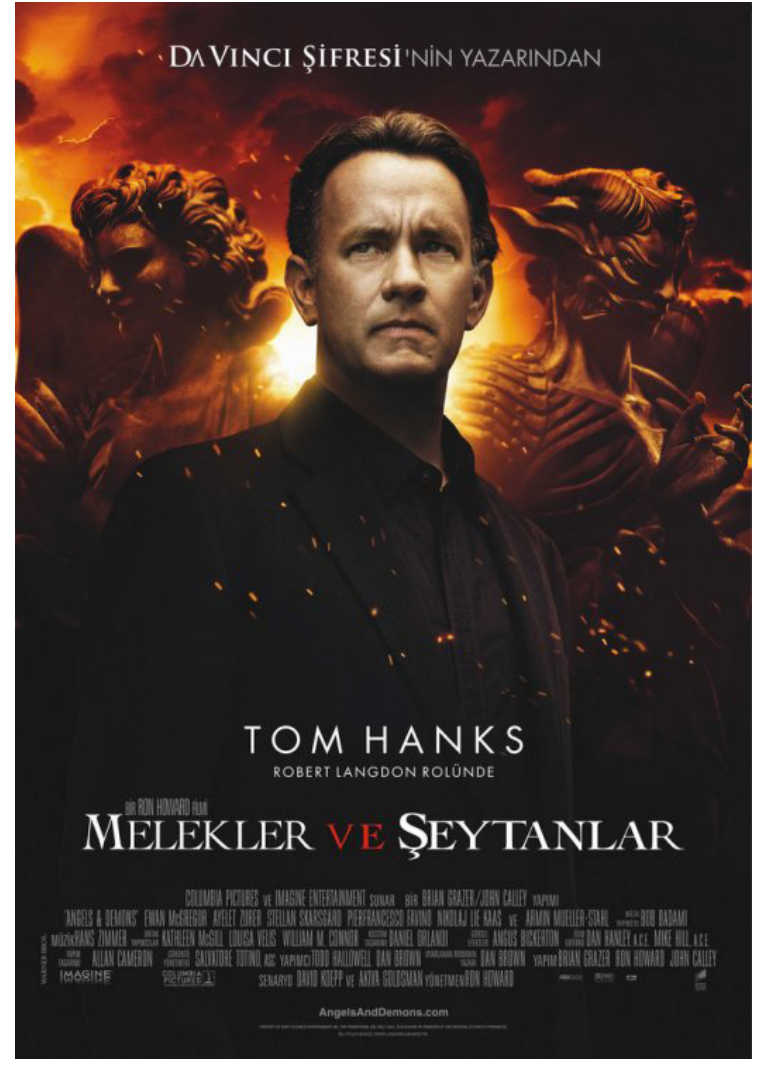

Resim 10. Melekler ve Şeytanlar filminin afişi.

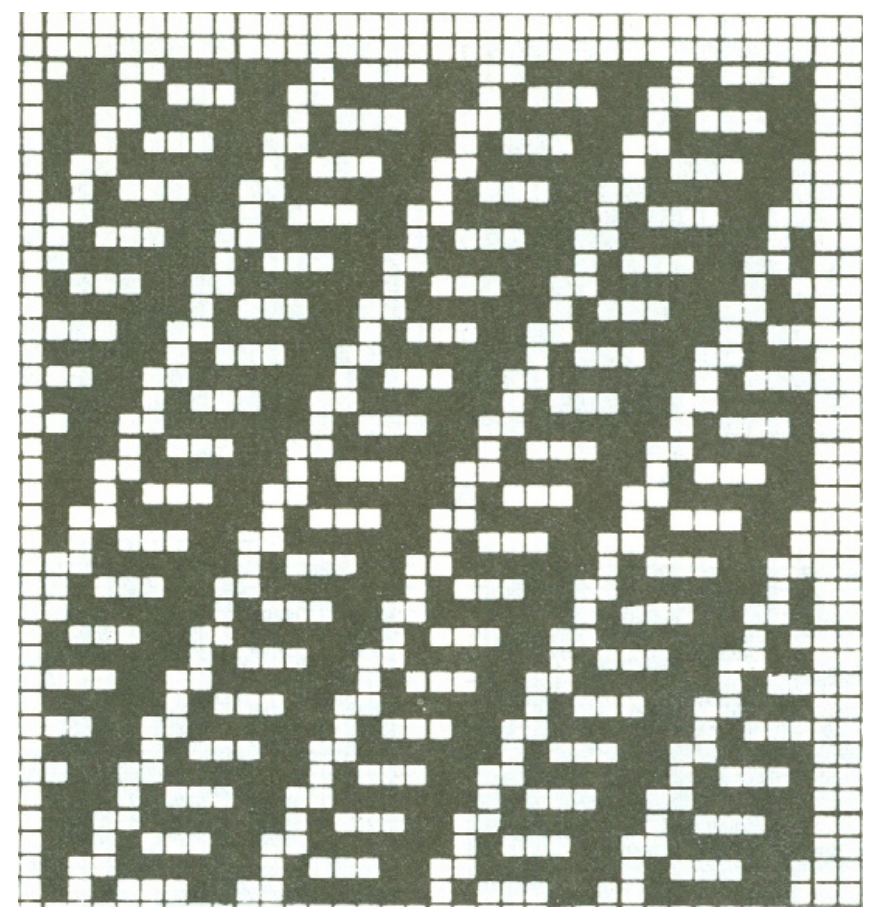

Resim 11. Motifli diyagonal örgü (Şeber ve Alpan, 1989: 71). 


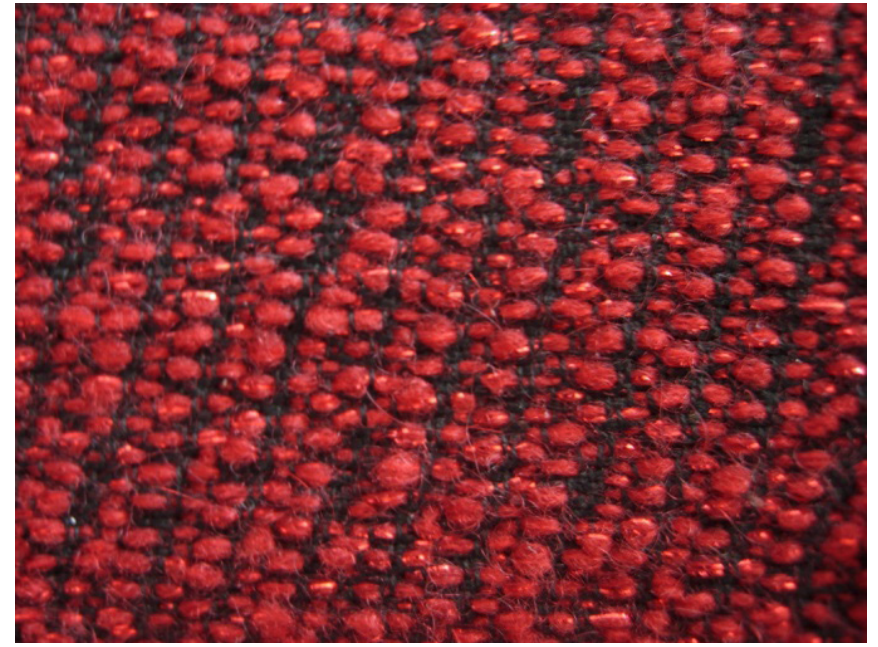

Resim 12. Giysilik Kumaş Tasarımı, Kevser Soysal, 2013.

\section{Tasarım 4}

Çıkış noktası: Titanik (1997). Bu tasarımda öğrenci, filmin yolculuk temasından ve filme de adını veren Titanik gemisinden ilham alarak, tasarım eskizinde enlemesine zigzag örgü kullanmıştır. Filmde geçen geminin batık ve deniz üzerindeki görüntülerinde yer alan renkler ipliklerle kumaş yüzeyine taşınmıştır. Örgü üzerinde boş olarak belirlenen alanlar atkı lansesi olarak değerlendirilirken zemin örgü bez ayağı seçilmiştir. Her bir zigzag için filmin teması ile ilişkili olarak mavi, beyaz, altın ve siyah renkler sırasıyla kullanılmış, yüzeyde inişli çıkışlı bir desen yakalanmıştır. Altın rengi simli iplik, aynı zamanda gemideki ihtişamı da sembolize etmiştir.

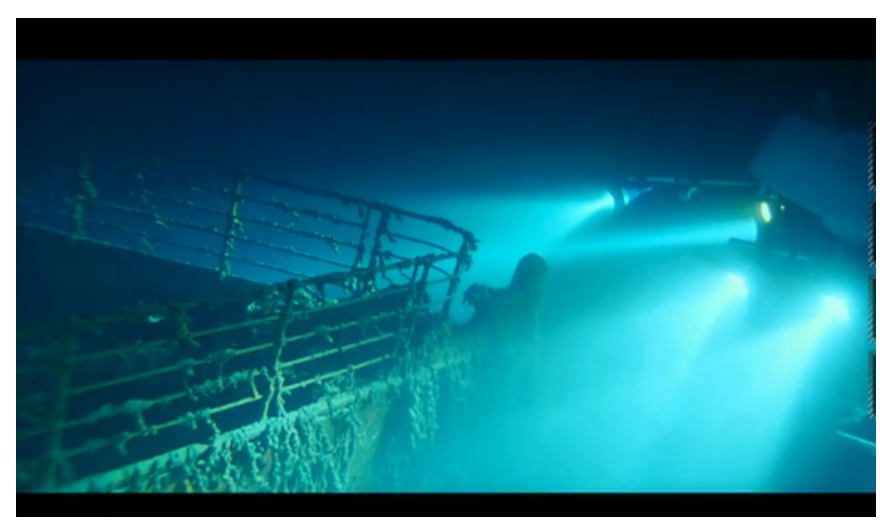

Resim 13. Titanik filminden bir sahne.

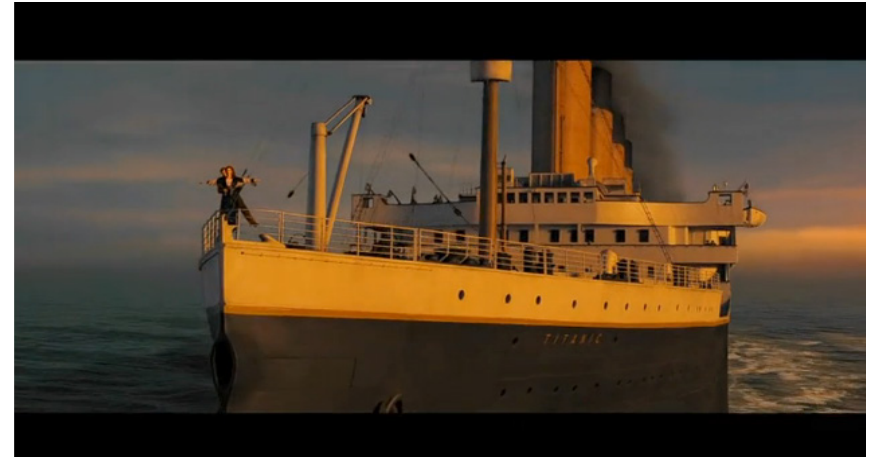

Resim 14. Titanik filminden bir sahne.

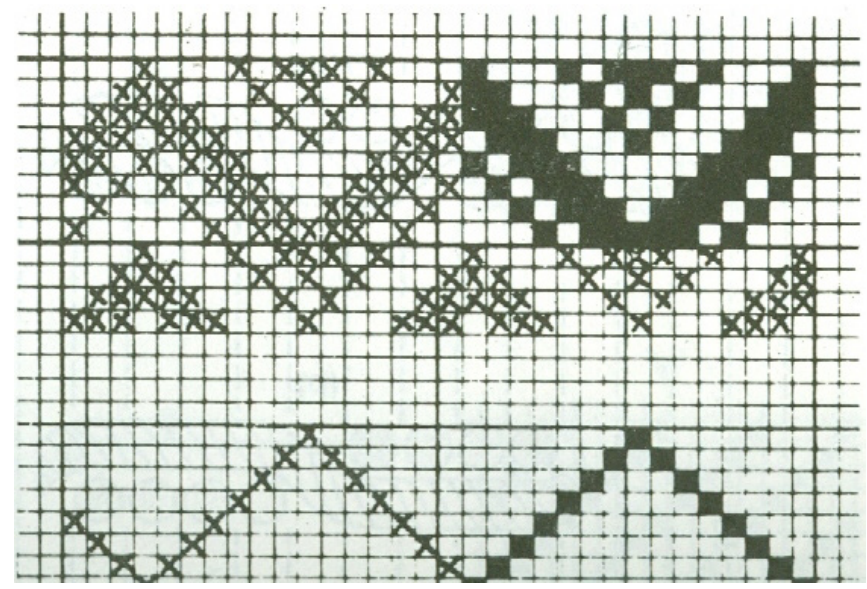

Resim 15. Enlemesine zigzag (Şeber ve Alpan,1989: 34).

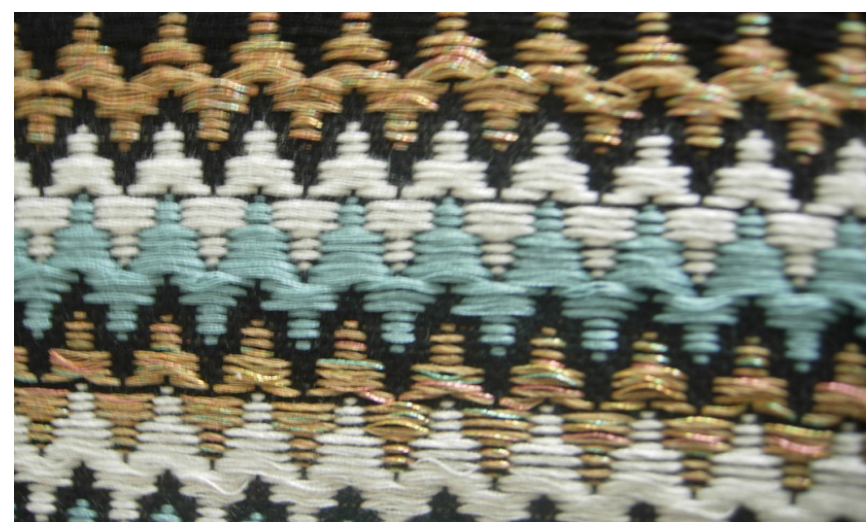

Resim 16. Giysilik Kumaş Tasarımı, Hacer Durmaz, 2013.

\section{Tasarım 5}

Çıkış noktası: Ya Sonra (2011). Bu tasarımın eskizinde merdiven örgü ve simetrisi birim rapor olarak ele alınmıştır. Filmin konusunu oluşturan evli bir çiftin inişli çıkışlı ilişkisi merdiven örgünün kullanılmasına neden olurken, 
film afişinde yer alan kırmızı renk de filmin romantik kurgusu ile ilişkilendirilmiştir. Zemin çözgüsü olarak siyah beyaz şerit düzeninde pamuklu iplik, zemin atkısı için siyah pamuk iplik seçilmiştir. Merdiven efektinin görüldüğü alanlar atkı lansesi olarak yorumlanmış ve filmin teması ile ilişkili olarak kırmızı renkli polyester/viskon iplik kullanılmıştır.

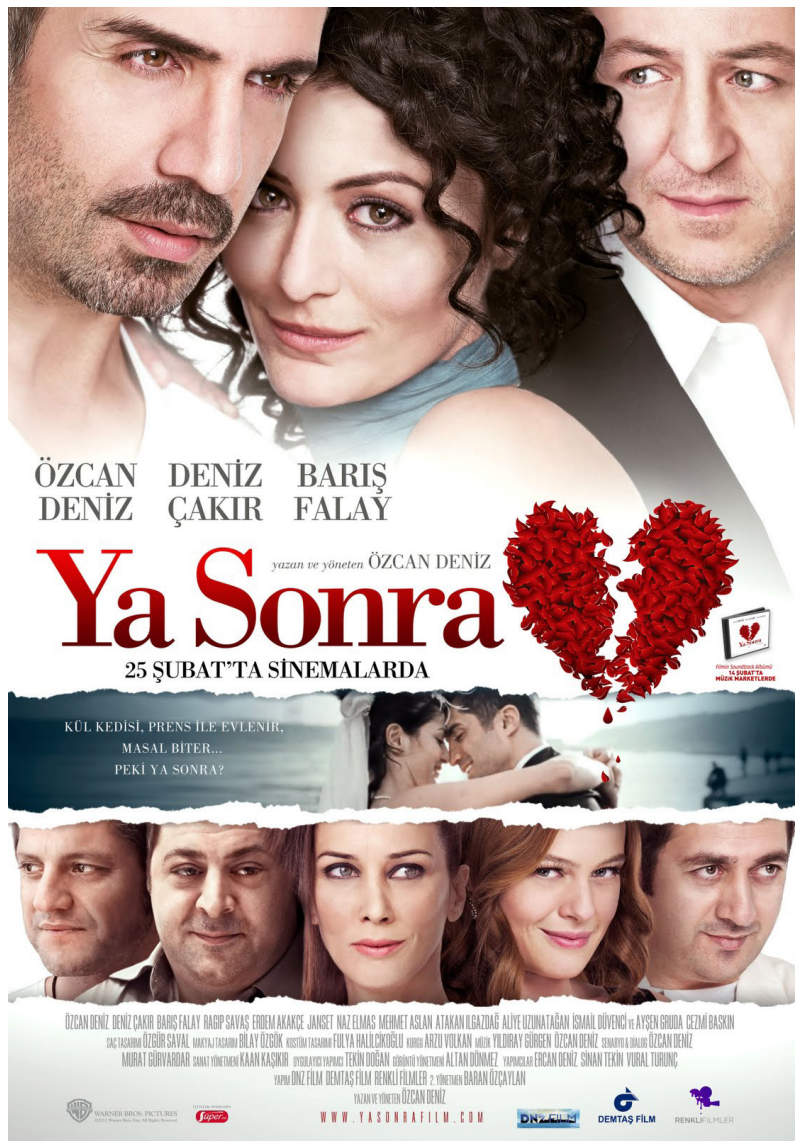

Resim 17. Ya Sonra filminin afişi.

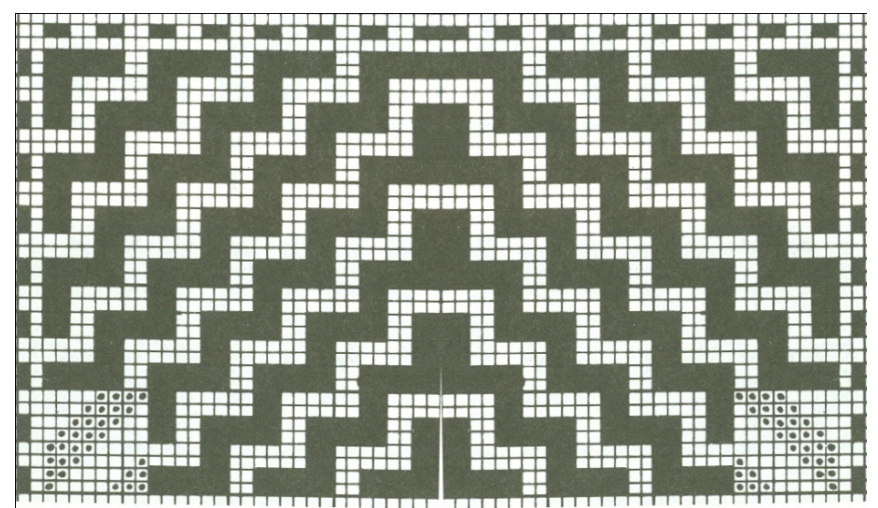

Resim 18. Merdiven örgü, (Şeber ve Alpan, 1989: 103).

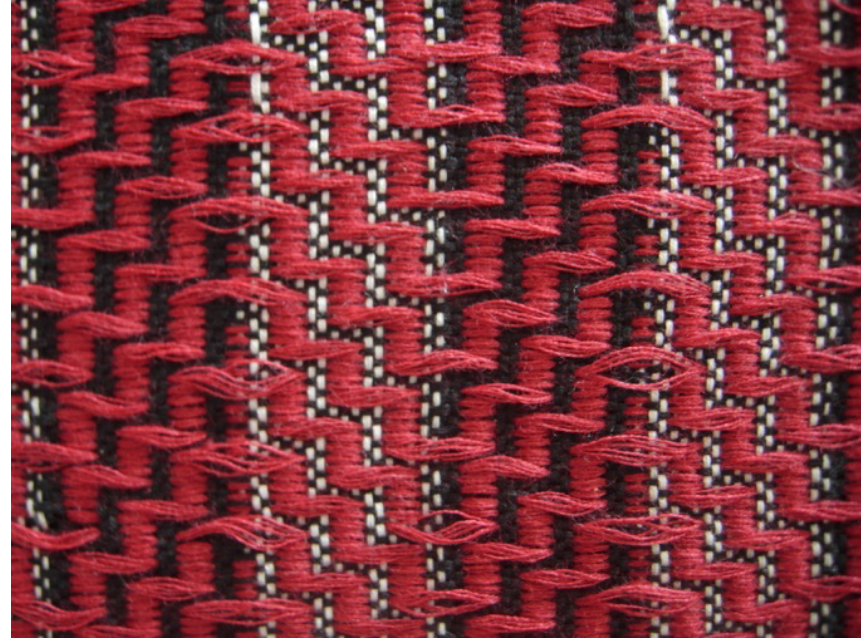

Resim 19. Giysilik Kumaş Tasarımı, İpek Tanrısever, 2013.

\section{Tasarım 6}

Çıkış noktası: Uzun Hikaye (2012). Bu tasarımın eskizinde yıldız efekti kullanılmıştır. Zemin örgüsü bez ayağı olan tasarımda renk seçimleri filmin teması ile bağlantılı olarak toprak tonları doğrultusundadır. Filmde ana karakter Ali'nin yazılarını yazdığı daktilonun tuşları ise yüzey düzenlemesindeki yıldız efekti için esin kaynağı olmuştur. Yıldız efektinin görüldüğü alanlarda atkı takviye ipliği olarak kullanılan yünlü sarı iplikler hem kabarık bir doku hem de desen oluşturmuştur.

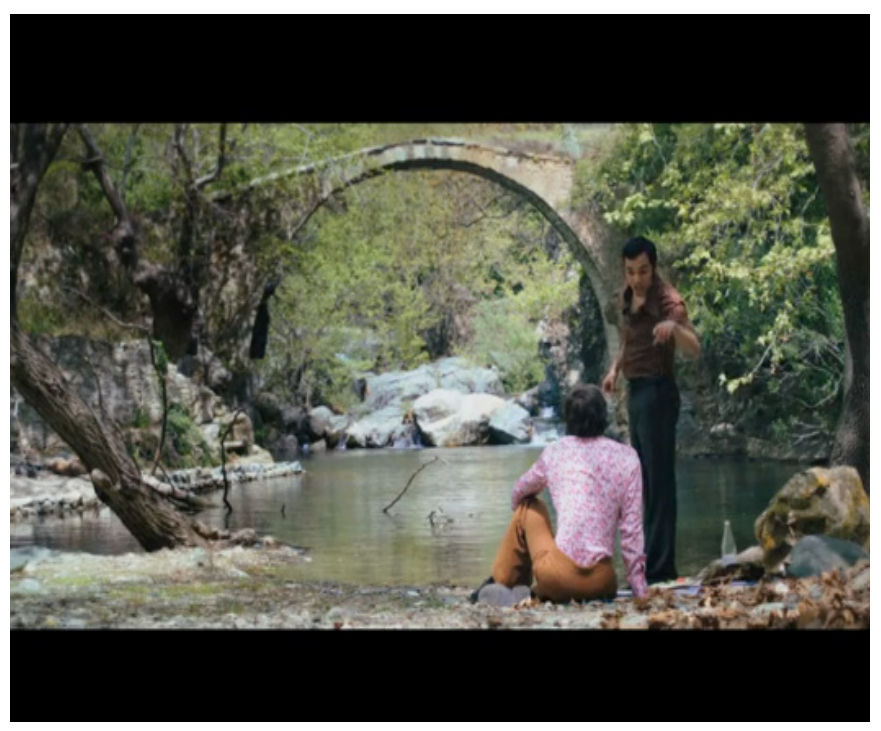

Resim 20. Uzun Hikaye filminden bir sahne. 


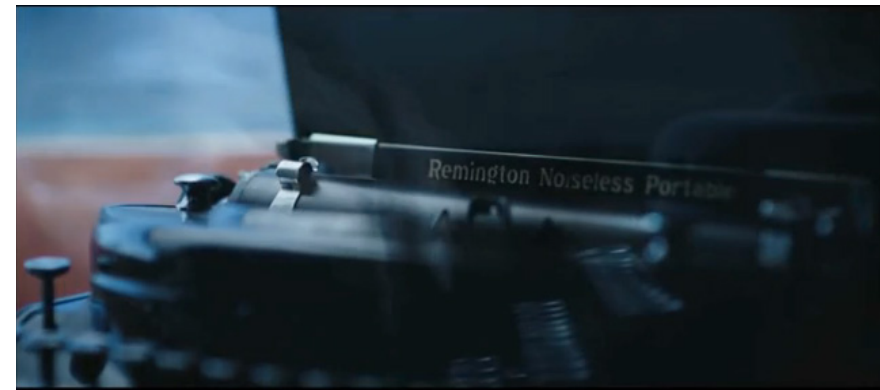

Resim 21. Uzun Hikaye filminden bir sahne.

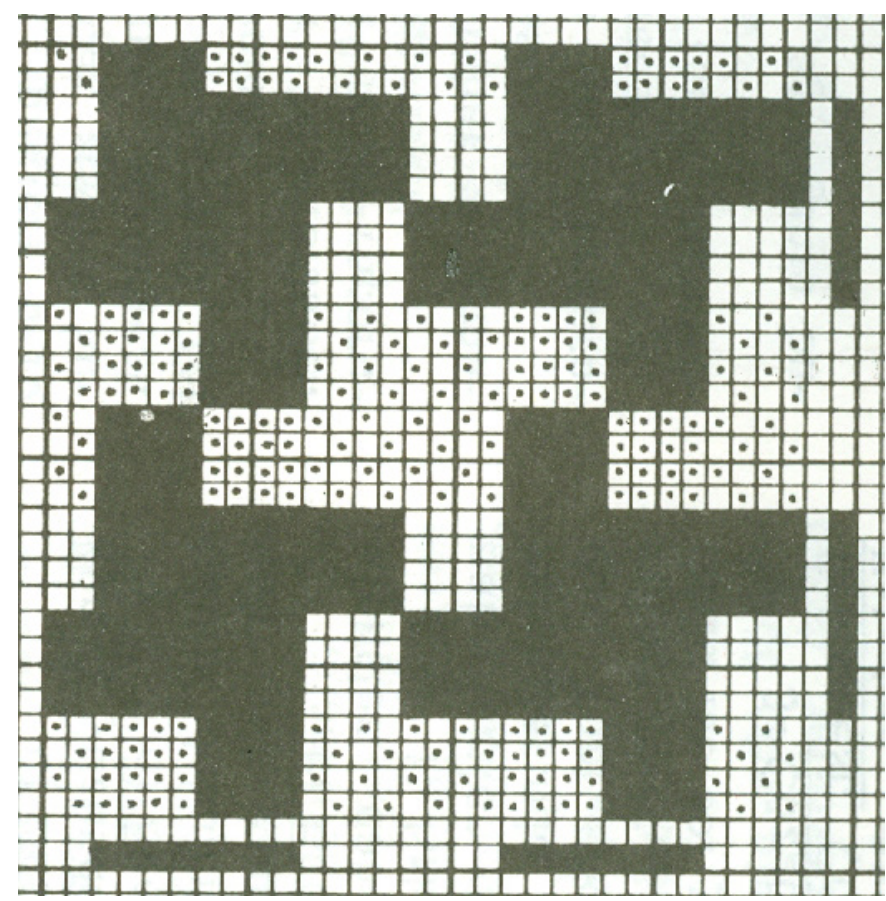

Resim 22. Özel örgülerle figürlü efekt, (Şeber ve Alpan, 1989: 113).

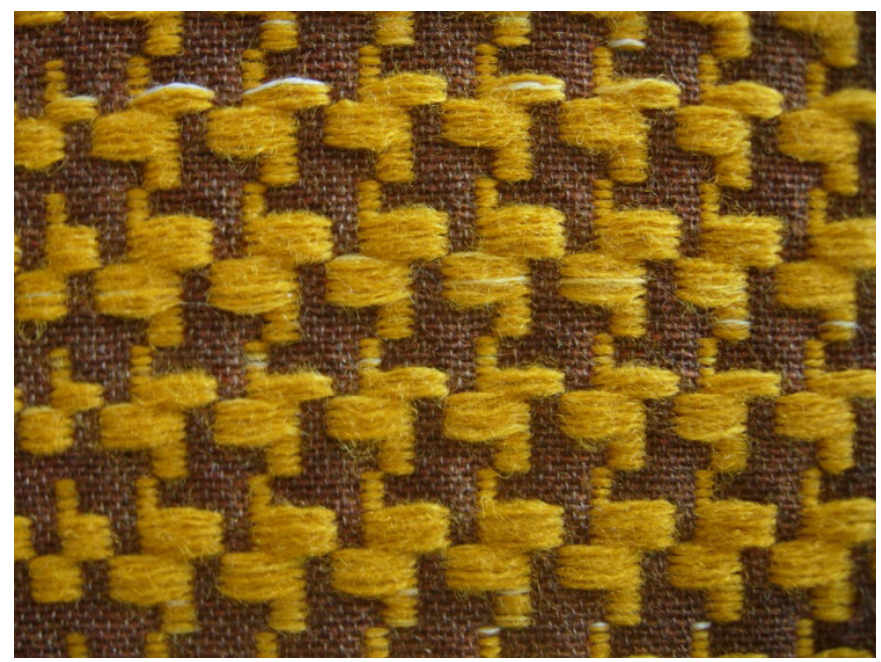

Resim 23. Giysilik Kumaş Tasarımı, Arzu Önal, 2013.

\section{Tasarım 7}

Çıkış noktası: Inception (2010). Bu tasarımda, filmde geçen bilinçaltı derinlik katmanlarından yola çıkılmış, yıldız efektleri oluşturulurken filmin jenerik tasarımındaki geometriden esinlenilmiştir. Tasarımda, yıldız efektleri farklı renkte ipliklerle atkı takviyesi olarak yorumlanırken atkı renk düzenindeki renk farkıııkları ile çizgili bir desen elde edilmiştir. Zemin örgüde bez ayağı örgü kullanılmıştır. Yıldız motifi olan alanlarda yünlü ipliklerin kullanılmasıyla yüzeyde alçak ve yüksek alanlardan oluşan hacimli bir etki elde edilmiştir.

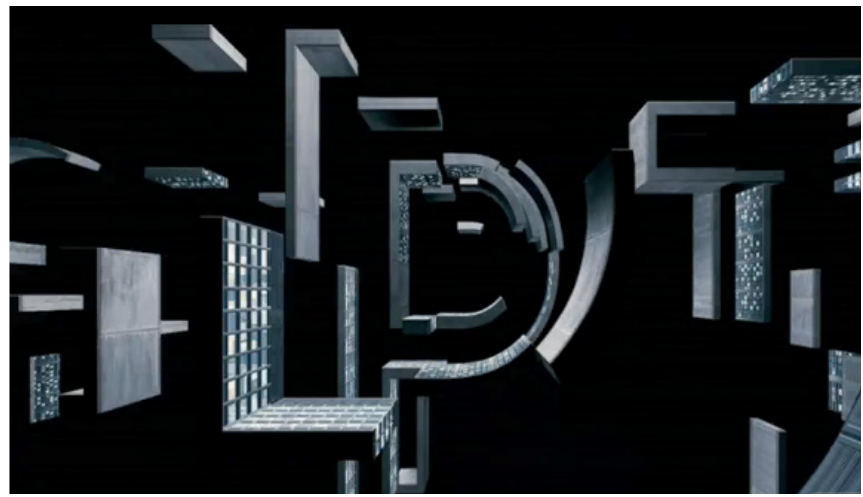

Resim 24. Inception filminden bir sahne.

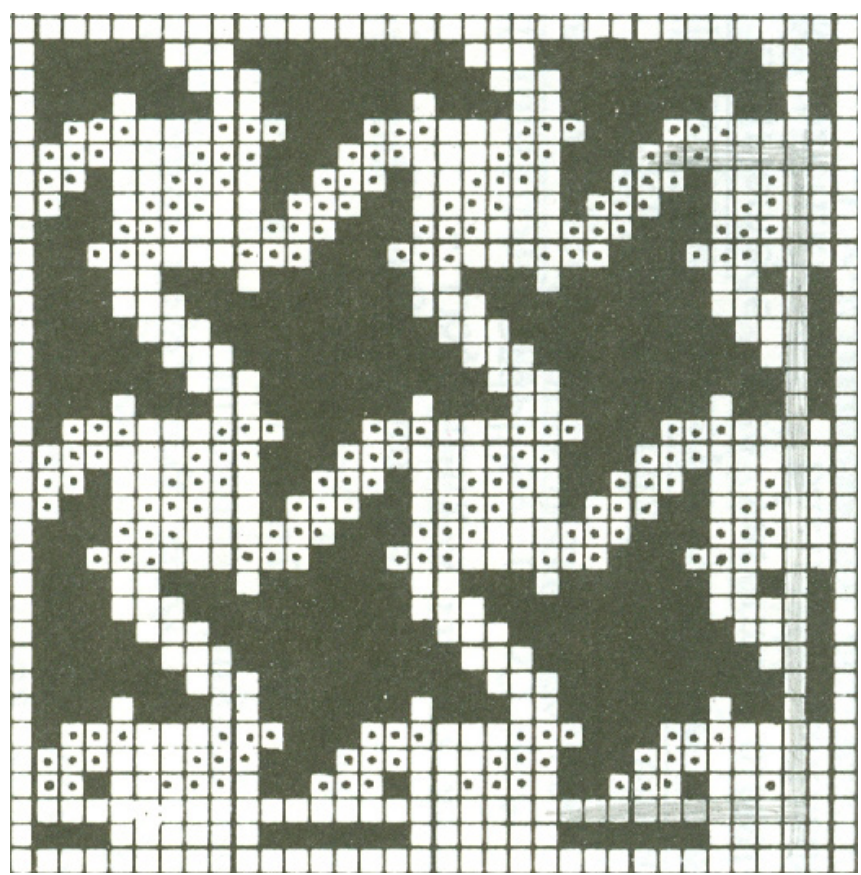

Resim 25. Özel örgülerle figürlü efekt (Şeber ve Alpan, 1989: 113). 


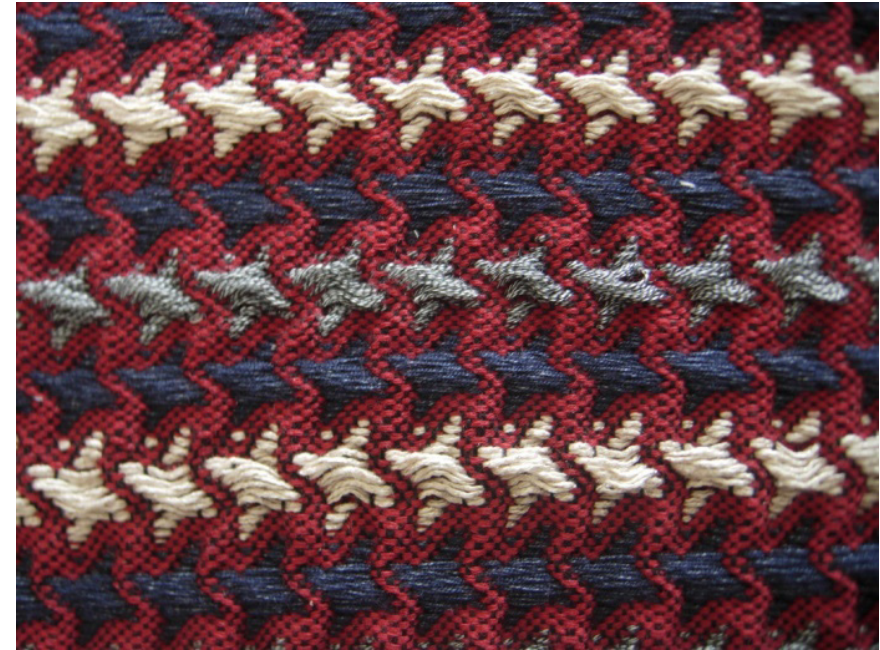

Resim 26. Giysilik Kumaş Tasarımı, Nehir Değirmenci, 2013.

\section{Sonuç}

Dokuma kumaş tasarımı, tüm tasarım alanlarında olduğu gibi, yaratıcı fikir ve malzemelerle yeni yorumlara ulaşılabilecek bir alandır. Yaratıcılık, tema seçimi, renk, doku ve yüzey araştırması aşamalarında olduğu kadar, yapı ve teknik seçimi aşamasında da rol oynayabilir. Bu nedenle, bu çalışmada renk örgü efektleri ile oluşturulan yüzeylerin lanseli yapı kullanılarak dokunmasıyla klasik anlayışın dışında yeni doku ve yüzey görünümleri için araştırmalar yapılmış, lisans düzeyinde öğrenim gören öğrencilerin yeni tasarımlar elde etmede varolandan farklı bir yöntem izlemeleri sağlanmıştır. Bu farklı uygulamalar sayesinde estetik ve teknik avantajlar sağlanmıştır:

- Lanseli yapıda renk örgü efektlerinin yorumlanmasıyla kumaş yüzeyinde bağımsız motifler yerine sürekli (all over) desen elde edilmiştir.

-Renk ve örgü efektleri ile elde edilen birimlerin lanseli yapı kullanılarak yorumlanmasıyla lanse iplikleri daha belirgin biçimde yüzeyde görünmüş, böylece klasik görünümlü kumaşların, ilave bir işleme gerek duyulmadan günümüz moda trendlerine uygun, üç boyutlu ve hacimli yüzeylere sahip olması sağlanmıştır.

-Atkı lanseli yapıda zemin örgüde bez ayağı kulla- nılmasıyla kumaşın boyutsal dayanıklılığı da tek katlı kumaşlara nazaran arttırılmıştır.

\section{Kaynakça}

Acuner, Altuğ (2001). Tasarımda Konstrüksiyon Esasları, İstanbul: Mart Matbaacılık.

Halaçeli Havva (2011). “Dokuma Kumaş Tasarımında Yaratıcılık”, 1. Sanat ve Tasarım Eğitimi Sempozyumu Dün Bugün Gelecek Bildiri Kitabı, Ankara, 575-578.

Imer, Zahide (1989). Dokuma Tekniği 1, Ankara: Sistem Ofset Ltd. Şti.

İmer, Zahide (1997). Dokuma Tekniği 2, Ankara: Cem web Ofset Ltd. Şti.

Köksal M., (2012). "Plastik Sanatlar ve Sinema İlişkisi”., İnönü Üniversitesi Sanat ve Tasarım Dergisi (2/4): 121-131

Önlü, Nesrin (2004). “Günümüz Giysilik Kumaşlarının Getirilen Yenilikler Işığında Tasarım ve Teknik Açıdan İncelenmesi”, Tekstil Maraton, Mart- Nisan (2), 12-23

Saçlıŏ̆lu, M., Saçlığlu, O., Akbostanı, İ., Çini, Ç., (2007). “Tekstilin Ördügü Ağlar Endüstri Zanaat ve Sanat”, P Dünya Sanatı Dergisi (44), 36-51

Sutton Ann, Sheehan Diane (1989). Ideas in Weaving, USA: Interweave Press.

Şeber, Bahattin ve Alpan, Dilek (1989). Kumaş Yapı Bilgisi, İstanbul: Alemdar Ofset.

\section{Görsel Kaynaklar}

Resim 1. Gülşah Bakır, renk-örgü efektli kumaş tasarımı, 2012.

Resim 2. Özge Çetinkaya, atkı lanseli kumaş tasarımı, 2013.

Resim 3. http://www.beyazperde.com/filmler/film-61445/

Resim 4. D 1/13 s örgüsü ve lanseli yapı ile açılımı, tam tekrarlı görünümü,

Resim 5. D 1/13 s örgüsü ve lanseli yapı ile açılımı, tam tekrarlı görünümü.

Resim 6. Giysilik kumaş tasarımı, Jiyan Erkil, 2013.

Resim 7. http://www.beyazperde.com/filmler/film-176639/ Erişim: 11.10.2014

Resim 8. Balıksırtı örgü (Şeber ve Alpan, 1989: 37)

Resim 9. Giysilik Kumaş Tasarımı, Ecem Baki, 2013.

Resim 10. http://www.beyazperde.com/filmler/film-124371/ Erişim: 11.10.2014

Resim 11. Motifli diyagonal örgü (Şeber ve Alpan, 1989: 71). 
Resim 12. Giysilik Kumaş Tasarımı, Kevser Soysal, 2013.

Resim 13. http://www.beyazperde.com/filmler/film-5818/ Erişim: 11.10.2014

Resim 14. http://www.beyazperde.com/filmler/film-5818/ Erişim: 11.10.2014

Resim 15. Enlemesine zigzag (Şeber ve Alpan,1989: 34).

Resim 16. Giysilik Kumaş Tasarımı, Hacer Durmaz, 2013.

Resim 17. http://www.beyazperde.com/filmler/film-189657Erişim: 11.10.2014

Resim 18. Merdiven örgü, (Şeber ve Alpan, 1989: 103).

Resim 19. Giysilik Kumaş Tasarımı, İpek Tanrısever, 2013.

Resim 20. http://www.beyazperde.com/ara/?q=uzun+hikaye Erişim: 11.10.2014

Resim 21. http://www.beyazperde.com/ara/?q=uzun+hikaye Erişim: 11.10.2014

Resim 22. Özel örgülerle figürlü efekt, (Şeber ve Alpan, 1989: 113).

Resim 23. Giysilik Kumaş Tasarımı, Arzu Önal, 2013.

Resim 24. http://www.beyazperde.com/filmler/film-143692/, Erişim: 11.10.2014

Resim 25. Özel örgülerle figürlü efekt (Şeber ve Alpan, 1989: 113).

Resim 26. Giysilik Kumaş Tasarımı, Nehir Değirmenci, 2013. 